\title{
FIVE LAWS OF LIBRARY SCIENCE: SEBUAH PEMIKIRAN YANG DINAMIS DARI RANGANATHAN
}

\author{
Rohana $^{1}$, Iwin Adryawin ${ }^{2}$ \\ Jurusan Ilmu Perpustakaan, Fakultas Ilmu Sosial dan Ilmu Politik \\ Universitas Muhammadiyah Mataram \\ rohana.mip@gmail.com
}

\section{INFO ARTIKEL}

\section{Riwayat Artikel:}

Diterima:....-...-..

Disetujui:...-...-...

\section{Kata Kunci:}

Ranganathan, IImu Perpustakaan

\begin{abstract}
ABSTRAK
Fokus penelitian ini adalah pemikiran Ranganathan mengenai konsep dasar perpustakaan yang dikenal dengan Lima Hukum IImu Perpustakaan dari Ranganathan. Tujuan penelitian ini adalah untuk mengetahui pemikiran ilmu perpustakaan dari tokoh Ranganathan sebagai pijakan dalam implementasi dan pengembangan perpustakaan ke depan. Metode penelitian menggunakan library research (penelitian literatur) dan bersifat deskriptif. Teknik pengumpulan data dilakukan dengan teknik baca catat. Kemudian dianalisis dengan teknik analisis isi.

Hasil penelitian ini adalah Konsep Five Laws of Library Science Ranganathan merupakan konsep yang dinamis, bukan sesuatu yang sudah sempurna dan final. Oleh karenanya, hukum Ranganathan tersebut harus senantiasa dikaji dan dikembangkan menurut kebutuhan dan visi, serta misi perpustakaan itu sendiri. Lima Hukum tersebut adalah 1. Books are for use (buku untuk dimanfaatkan). 2. Every reader his book (setiap pembaca terdapat bukunya). 3. Every book its reader (setiap buku terdapat pembacanya). 4. Save the time of the reader (hemat waktu pembaca). 5. A library is a growing organism (perpustakaan adalah organisme yang berkembang).
\end{abstract}

\section{A. PENDAHULUAN}

Dalam dunia perpustakaan, Ranganathan adalah salah satu tokoh perpustakaan yang namanya cukup terkenal dan banyak memberikan kontribusi positif terhadap perkembangan dunia perpustakaan. Pemikiran-pemikirannya yang ia tuangkan dalam classification ${ }^{11}$ and indexing theory dan Colon Classification ${ }^{1}$ masih terus digunakan di dalam kajian-kajian ilmu perpustakaan di seluruh dunia dan mempengaruhi evolusi dari sistem DDC/Dewey Decimal Classification ${ }^{2}$.

Selain karya tersebut di atas, pemikiran Ranganathan yang tak kalah populernya sehingga sampai saat ini masih dirujuk dan dijadikan

\footnotetext{
${ }^{1}$ Abulfazal M. Fazle Kabir, "Ranganathan: A Universal Librarian" dalam Journal of Educational Media \& Library Science, 40: 4 (June 2003), hlm. 453 dan 456-459.

2 Sri Rohyanti Zulaikha, "Kontribusi S.R. Ranganathan dalam Perkembangan Ilmu Perpustakaan Dewasa Ini" dalam Fihris Jurnal Ilmu Perpustakaan dan Informasi Vol. III No. 1 (Januari-Juni 2008), (Yogyakarta: Jurusan IPI Fakultas Adab UIN Sunan Kalijaga, 2008), hlm. 79.
}

landasan dalam pengembangan perpustakaan adalah pemikirannya yang ia tuangkan dalam Lima Hukum dari Ilmu Perpustakaan. Lima hukum inilah yang menjadi dasar dan merupakan satu-satunya yang jelas dari suatu fungsi-fungsi dan tanggungjawab perpustakaan. ${ }^{3}$ Namun demikian, lima hukum ini tak lantas menjadi hukum yang sudah final atau tak perlu dikembangkan lagi, melainkan harus tetap digali dan dikembangkan maknanya dalam rangka mendekati suatu kesempurnaan dalam bidang ilmu perpustakaan4. Hal ini menunjukkan bahwa hukum (dalam bentuk apapun) tetaplah sebuah pemikiran yang tidak final, tidak mutlak benar, dan dapat selalu diinterpretasi selama ilmu perpustakaan ini ada. Akan tetapi konsep dasar dalam pengembangan perpustakaan tak bisa luput dari pemikiran ini karena mencakup

\footnotetext{
${ }^{3}$ Ibid. hlm. 82

4 Syihabuddin Qalyubi dkk., Dasar-dasar Ilmu Perpustakaan dan Informasi, (Yogyakarta: Jurusan Ilmu Perpustakaan dan Informasi Fakultas Adab, 2007), hlm. 287
} 
berbagai elemen penting dalam dunis kepustakawanan.

Tidak berlebihan jika pengembangan pemikiran Ranganathan yang terkenal ini terus dilakukan dalam upaya menemukan proses dinamisasi. Karena tidak dapat dipungkiri bahwa segala pemikiran manusia hadir dalam ruang, waktu, dan kondisi yang berbeda. Sehingg Lima Hukum Ranganathan adalah hukum (pemikiran) yang dinamis dan bisa terus dikembangkan sesuai perkembangan masa kini. Interpretasi dengan segala keunikannya akan sangat dipengaruhi pula oleh sang interpreter yang memiliki latar belakang sosio-kultural yang berbeda di setiap tempat dan generasi. Tentu generasi milenial seperti sekarang memiliki interpretasi dan kajian yang lebih meluas karena perkembangan teknologi dan informasi yang semakin pesat.

\section{B. METODE PENULISAN}

Penelitian ini merupakan jenis penelitian yang bersifat literer (library research) dalam pengertian penelitian ini akan didasarkan pada data tertulis yang berbentuk buku, ensiklopedia, Jurnal atau artikel lepas yang terkait dengan pemikiran Ranganathan khususnya yang berkaitan dengan konsep Lima Hukum Ilmu Perpustakaan.

Penelitian ini bersifat deskriptif analisis yaitu penelitian yang menghasilkan data deskriptif berupa kata-kata tertulis atau lisan dari orang-orang dan perilaku yang dapat diamati atau dijadikan sumber informasi. Dalam penelitian kualitatif penggunaan data dan analisis deskriptif dipilih untuk menjawab pertanyaanpertanyaan "mengapa, alasan apa dan bagaimana terjadinya" dari suatu fenomena sosial dalam kehidupan masyarakat, sehingga dalam penelitian ini penulis menggunakan pendekatan kualitatif.

Teknik pengumpulan data dilakukan dengan teknik baca dan catat. Artinya, pengumpulan data dapat dikatakan selesai kalau dari bahan-bahan (dokumen) yang terkumpul itu ditulis atau dicatat.
Sedangkan teknik pengolahan data dilakukan dengan cara deskriptif dan analisis.

\section{BIOGRAFI RANGANATHAN}

Namanya Dr. Syiyali Ramamrita Ranganathan. Selanjutnya orang mengenalnya dengan S.R Ranganathan. Lahir di Madras, India pada bulan Agustus 1892 wafat pada 27 September 1972 di Bangalore Mysore. Ia seorang ahli Matematika (dosen Matematika di Universitas Madras) dan juga seorang pustakawan cerdas pada masa itu. Selain itu, ia juga seorang pendidik, pengajar, dan penulis produktif dalam bidang ilmu perpustakaan. Pada tahun 1924, ia ditawarkan suatu posisi pustakawan di University, dengan syarat ia bepergian ke University College di London untuk belajar mengenai ruang lingkup kerja kepustakawan zaman ini. selama studistudinya di Britania Raya, S.R Ranganathan mengunjungi berbagai perpustakaan umum dan perguruan tinggi di sepanjang negeri, yang membantu dia untuk berfokus pemikirannya di dalam bidang-bidang klasifikasi, cataloguing, dan jasa perpustakaan. S.R Ranganathan melihat bahwa perpustakaan sebagai unsur esensial dalam membantu masyarakat-masyarakat untuk tumbuh dan berkembang dengan subur melalui penyebaran yang melek huruf, yang membuat dia berfokus studistudinya di dalam area jasa pustaka. 5

S.R Ranganathan banyak menghabiskan waktunya untuk menekuni bidang perpustakaan baik menjadi pustakawan (1924), menjadi profesor ilmu perpustakaan (1945-1954), sampai menjadi penulis di bidang ilmu perpustakaan yang disumbangkannnya kepada dunia dan masih dirujuk hingga kini. Di dalam menulis karya-karya besarnya, termasuk Five Laws of Library Science merupakan karya yang awalnya dilatarbelakangi oleh pengalaman panjang selama ia menjadi pustakawan. Setelah ia berkeliling dari perpustakaan-perpustakaan umum dan universitas ke perpustakaan-perpustakaan lainnya, ia 
mendapat banyak pengalaman dan pengetahuan tentang bagaimana kondisi perpustakaan yang ada, bagaimana jasa yang diberikan, dan bagaimana teknis yang digunakan. Dalam konteks ini, S.R Ranganathan kemudian menulis pemikiranpemikiran umumnya dalam bentuk prinsip-prinsip yang lebih khusus, sistematis, dan maknanya luas seperti Five Laws of Library Science ini.

Lima hukum dari ilmu perpustakaan Ranganathan ini merupakan hasil dari segudang pengalaman yang ia dapat pada masa ia menjadi pustakawan, pengajar, pendidik, dan pengelola organisasi perpustakaan. Hal inilah yang menjadikan tulisan atau karya-karyanya bermakna luas, selalu dapat dikembangkan (dinamis), dan relevan hingga saat ini. Di Era global yang canggih dengan teknologi informasi ini, hukum perpustakaan yang ditulis Ranganathan masih terus dijadikan rujukan, lalu dikembangkan menjadi prinsip yang lebih sempurna.

Noruzi dalam Zulaikha mengatakan bahwa berdasarkan hukum Ranganathan, Jim Thompson (1992) membuat pernyataan bahwa terdapat hubungan yang signifikan antara hukum yang dihasilkan oleh Ranganathan dengan kemajuan perkembangan teknologi informasi sekarang ini, yaitu bahwa : Book are for profit, every reader his bill, every copy its bill, take the cash of the reader, and the library is a groaning organism ${ }^{6}$. Hal ini mengandung makna bahwa perpustakaan dan web harus ada untuk melayani seluruh kebutuhan pemustaka. Apalagi teknologi informasi setiap saat berkembang dan mengalami kemajuan pesat di berbagai lini. Zaman yang berbeda dari Ranganathan hingga sekarang ini menuntut kita untuk selalu mengembangkan pemikiran-pemikiran baru sesuai kondisi saat ini.

Five Laws of Library Science Ranganthan merupakan salah satu bentuk pemikiran yang harus senantiasa dikaji dan dikembangkan, selanjutnya

\footnotetext{
${ }^{6}$ Alireza Noruzi, "Application of S.R Ranganathan Laws to the Web". Dalam Webology, Volume 1, Number 2, Desember 2004, dalam Sri Rohyanti Zulaikha, "Kontibusi...hlm. 76.
}

diaplikasikan sesuai kebutuhan perpustakaan era sekarang. Karena pada dasarnya Ranganathan pun menulis karyanya tersebut atas dasar pengalaman atau pengembaraan panjangnya selama menjadi pustakawan. hal ini berarti bahwa apa yang ia tulis tak lepas dari kondisi saat itu, dan bukan kondisi saat ini. Dinamisasi karya Ranganathan pun menjadi keharusan apabila menginginkan perpustakaan yang lebih baik dan lebih relevan dengan masyarakat pengguna.

\section{KARYA-KARYA RANGANATHAN}

Adapun karya-karya Ranganathan yang masih populer hingga sekarang antara lain:

1. Ranganathan, S. R. (1931). The Five Laws of Library Science. Madras Library Association (Madras, India) and Edward Goldston (London, UK).

2. Ranganathan, S. R. (1937). Prolegomena to Library Classification. The Madras Library Association. 2nd Ed, The Madras Library Association, 1957. 3rd edition. London: Asia Publishing House, 1967.

3. Ranganathan, S. R. (1951a). Classification and Communication.

University of Delhi (Delhi, India).

4. Ranganathan, S. R. (1951b). Documentation Genesis and Development. Vikas Publishing House (Delhi, India).

5. Ranganathan, S. R. (1967). Prolegomena to Library Classification. Asia Publishing House (New York).

6. Ranganathan, S. R. (1989). Philosophy of Library Classification. Sarada Ranganathan Endowment for Library Science (Bangalore, India).

7. Colon Classification Science

8. Classified Catalogue Code (1934)

9. Theory of Library Catalogue (1938)

10. Element of Library Classification (1945)

11. Haedings and Canons (1955). 


\section{E. LIMA HUKUM ILMU PERPUSTAKAAN DARI RANGANATHAN: SEBUAH PEMIKIRAN YANG DINAMIS}

Seperti yang telah disinggung di atas, bahwa Five Laws of Library Science yang ditulis oleh Ranganathan merupakan pemikiran yang dinamis. Artinya bahwa pemikiran beliau tersebut masih dapat dikembangkan, diperbaiki, ataupun dirubah sesuai kondisi saat ini. kalau dulu pada masa Ranganathan, karya tersebut ditulis saat teknologi informasi masih belun terlalu pesat perkembangannya, maka pada era informasi ini konsep hukum Ranganathan tersebut menjadi sesuatu yang sudah lalu. Akan tetapi, sesuatu yang sudah lalu tak lantas hilang, melainkan tetap ada, namun harus disesuaikan dengan zaman, ruang, dan waktu saat ini.

Five Laws of library Science Ranganathan 7 tersebut adalah:

1. Books are for use (buku untuk dimanfaatkan)

2. Every reader his book (setiap pembaca terdapat bukunya)

3. Every book its reader (setiap buku terdapat pembacanya)

4. Save the time of the reader (hemat waktu pembaca)

5. A library is a growing organism (perpustakaan adalah organisme yang berkembang).

\section{Buku untuk dimanfaatkan}

Definisi perpustakaan yang selama ini masih dirujuk bahwa perpustakaan adalah sebuah ruangan, bagian sebuah gedung, ataupun gedung itu sendiri yang digunakan untuk menyimpan buku dan terbitan lainnya yang biasanya disimpan menurut tata susunan tertentu untuk digunakan

\footnotetext{
${ }^{7}$ Ranganathan, Shiyali R.amamrita. The Five Laws of Library Science. (London: Edward Goldston, Ltd,; Madras: Madras Library Association, 1993). Lihat juga B K Sen,

"Ranganathan's Fife Laws" dalam Annals of Library and Information Studies, Vol, 55, June 2008, pp. 87-90. Lihat juga Abulfazal M. Fazle Kabir, "Ranganathan: A Universal...hlm. 454-455.
}

pembaca ${ }^{8}$ sudah mengalami fase lewat karena perubahan besar dalam dunia perpustakaan dan informasi telah terjadi. Perpustakaan tidak lagi hanya tempat menyimpan koleksi-koleksi yang telah ada, namun perpustakaan mempunyai fungsi yang lebih dari itu, yaitu mengembangkan koleksikoleksinya dan mempromosikan semua buku-buku tersebut untuk dimanfaatkan.

Prinsip dasar yang digunakan pada hukum pertama ini mengandung dasar bahwa buku itu ada untuk digunakan. Hukum yang pertama ini memberikan batasan definisi kepada dua konsep yaitu perpustakaan yang dapat diakses secara terbuka dan tertutup dan pada perpustakaan yang harus menentukan peralatan dan perabotan perpustakaan untuk menempatkan koleksi secara baik dan benar. Koleksi perpustakaan di ambil dari ruang pengolahan dan dibawa keluar diletakkan di rak yang terbuka. Dalam hal ini, rak perpustakaan harus mampu diakses dengan baik oleh pemustaka. Sehingga perpustakaan harus ditempatkan di tengah-tengah atau di dekat civitas akademika yang ada. Tetapi, dimanapun lokasi perpustakaan, bagaimanapun jam buka layanannya, bagaimanapun tipe perabotannya serta bagaimanapun cara mendapatkan buku di perpustakaan, staf perpustakaannlah yang paling bertanggungajwab terhadap perpustakaan 9 .

Selain hal tersebut di atas, perpustakaan bukan hanya menyiapkan kemudahan dalam mendapatkan buku di rak saja, melainkan bagaimana buku-buku tersebut dapat digunakan dengan baik dan tepat sasaran. Prinsip Ranganathan di atas menunjukkan bahwa buku sebagai sebuah informasi harus bisa dimanfaatkan pemustaka sesuai dengan kondisi dan kebutuhan pemustaka itu. Maka, dalam hal ini kita dapat mengembangkan prinsip tersebut menjadi buku itu ada untuk dimanfaatkan dan diaplikasikan. Senada

\footnotetext{
${ }^{8}$ Sulistyi-Basuki, Pengantar Ilmu Perpustakaan, (Jakarta: Penerbit PT Gramedia Pustaka Utama, 1993), hlm. 3.

${ }^{9}$ Sri Rohyanti Zuaikha, "Kontribusi...hlm. 83.
} 
dengan fungsi perpustakaan itu sebagai agent of social change di dalam bermasyarakat, berbangsa, dan bernegara. Dengan demikian, koleksi-koleksi yang dikembangkan adalah koleksi yang sesusi kondisi sosial, ekonomi, kultur, agama, dan kebutuhan masyarakat itu sendiri, agar semua koleksi tidak hanya dibaca melainkan diaplikasikan secara nyata di dalam kehidupan. Maka dalam hal ini salah seorang tokoh perpustakaan Indonesia menambahkan fungsi perpustakaan yaitu sebagai hegemoni. Artinya, seseorang atau sekelompok orang yang membaca kemudian memanfaatkaan informasi yang dibaca atau diperoleh di perpustakaan dapat dipengaruhi oleh bacaan tersebut baik dalam kehidupan sosial, politik, ekonomi, agama, pendidikan dan sebagainya.

Oleh karena itu, setiap perpustakaan memiliki visi misi yang berbeda sesuai dengan keadaan dan arah tujuan dari perpustakaan itu sendiri, misalnya perpustakaan khusus. Hal ini menandakan bahwa buku atau bacaan memiliki pengaruh besar terhadap kehidupan. Sehingga setiap perpustakaan dituntut untuk menyediakan dan melayankan buku untuk dimanfaatkan. Tentu kondisi ini didapat apabila buku sesuai dengan kebutuhan pemustaka.

\section{Setiap pembaca terdapat bukunya}

Pada hukum ini, prinsip yang digunakan mengacu pada kebutuhan pemustaka, di mana setiap perpustakaan dituntut untuk mampu menyediakan buku sesuai kebutuhan pemustaka. Akan tetapi pertanyaan fundamental yang masih diperdebatkan adalah "Apakah semua koleksi harus didapatkan pemustaka, sementara dana untuk membeli koleksi tersebut terbatas?”. Dengan dasar ini prinsip hukum kedua ini bisa dikembangkan sesuai kondisi perpustakaan itu sendiri. Perpustakaan bisa melihat siapa pengguna (mayoritas) yang memanfaatkan perpustakaan itu sendiri. Di sinilah lahir visi dan misi perpustakaan sebagaimana yang penulis sebut di atas sebagai sebuah jawaban atas kebutuhan pemustaka terhadap koleksi tertentu. Dalam konteks ini perpustakaan menyesuaikan dengan visi dan misi yang ada.

Kerjasama antar perpustakaan yang satu dengan yang lain menjadi keharusan dalam mengatasi keterbatasan buku yang disebabkan oleh keterbatasan dana. Dan pustakawan yang mengelola dibidang pengadaan koleksi harus bisa memaksimalkan sebaik mungkin dana yang ada serta harus peka terhadap kebutuhan pemustaka. Kecanggihan teknologi saat ini memungkinkan sekali para pemustaka memperoleh bacaan dari sumber mana saja yang tersedia di internet, namun hal ini masih butuh bimbingan pustakawan agar informasi yang didapatkan valid dan akurat.

\section{3. setiap buku terdapat pembacanya}

Prinsip hukum ketiga ini menekankan adanya relasi yang harmonis antara koleksi dan pemustaka. Perpustakaan tidaklah berarti, walaupun koleksinya bergudang-gudang tanpa adanya keterkaitan atau bangunan relasi yang baik antara koleksi dan pemustaka. Karenanya, perlu ada perbaikan terus layanan terhadap pemustaka ini, khususnya dalam melakukan penelusuran terhadap koleksi yang dibutuhkan. Perpustakaan, jika menerapkan konsep ini, tidak akan pernah menyulitkan pemustaka dalam mencari informasi atau koleksi di perpustakaan.

\section{Hemat waktu pembaca}

Prinsip ini menekankan pada kemudahan dalam menemukan koleksi yang dibutuhkan pemustaka. Jangan waktu mencari koleksi tersebut jauh lebih besar atau lebih banyak dari pada koleksi yang didapat. Aturan-aturan yang menyulitkan, pelayanan yang lambat, dan kesukaran dalam menelusur harus dihilangkan agar waktu pemustaka lebih hemat dan teratur. Perpustakaan dituntut untuk terus memperbaiki sistem yang ada, baik itu aturan, kebijakan, atau operasionalisasinya. Prinsip keempat ini terlihat begitu dinamis terutama di era informasi ini. Layanan perpustakaan berbasis online seperti OPAC sangat 
membantu dalam peminjaman dan pengembalian yang efisien. Begitu juga dalam bimbingan pemustaka (user education) sangat dimungkinkan berjalan dengan baik melalui medsos seperti wa, fb, instagram, email, dan lain sebagainya. Layanan berbasis online merupakan pengembangan atas penapsiran prinsip keempat yang dituangkan Ranganathan dengan begitu sederhana namun tetap relevan sepanjang masa.

5. Perpustakaan adalah organisme yang berkembang

Hukum yang terakhir ini menjelaskan kepada kita bahwa yang terpenting dari sebuah perpustakaan adalah bahwa perpustakaan itu selalu tumbuh dan berkembang serta berubah dan akan selalu mengalami hal seperti itu. Koleksi perpustakaan selalu bertambah dan berubah, teknologi terus berkembang maju dan budget juga selalu mengikuti perubahan itu. Perubahanperubahan yang kompleks tersebut harus diantisipasi dan diimbangi dengan manajemen yang baik ${ }^{10}$.

Prinsip hukum yang kelima ini merupakan proses perjalanan lembaga (apapun) itu yang tidak pernah lepas dari perkembangan dan kemajuan ilmu pengetahuan manusia, sehingga dalam hal ini perpustakaan harus mampu menghadapi dan menyesuaikan diri dengan perkembangan itu sendiri. Kepekaan lembaga dan yang terkait adalah suatu keniscayaan yang harus dilakukan. Jika tidak, perpustakaan akan tenggelam dalam paradigma lama dan sulit maju. Di sini resistensi (penolakan) akan perubahan itu bisa menjadi dosa sosial yang berakibat mundurnya bangsa ini.

\section{F. PENUTUP}

$\begin{array}{ccr}\text { Adanya } & \text { perpustakaan merupakan } & \text { wujud } \\ \text { perkembangan } & \text { sebuah masyarakat. } & \text { Kini, } \\ \text { perkembangan } & \text { dunia yang ditandai dengan } \\ \text { perkembangan } & \text { teknologi informasi yang cepat }\end{array}$

menuntut perpustakaan untuk mengembangkan sayapnya sesuai perkembangan yang terjadi. Konsep Five Laws of Library Science Ranganathan merupakan konsep yang dinamis, bukan sesuatu yang sudah sempurna dan final. Oleh karenanya, hukum Ranganathan tersebut harus senantiasa dikaji dan dikembangkan menurut kebutuhan dan visi, serta misi perpustakaan itu sendiri. Dinamisasi hukum (apapun itu) merupakan bentuk dinamisnya pemikiran masyarakat dalam menyikapi situasi dan era yang berbeda dari sebelumnya.

\footnotetext{
${ }^{10}$ Rose Mary Magriil and John Corbin, Aqcuisition management and collection development in libraries. $2^{\text {nd }}$ ed. (Chicago: American Library Association, 1989), dalam Sri Rohyanti Zulaikha, "Kontibusi...hlm. 88.
} 


\section{DAFTAR PUSTAKA}

Kabir, Abulfazal M. Fazle, "Ranganathan: A

Universal Librarian" dalam Journal of

Educational Media \& Library Science, 40: 4

(June 2003.

Ranganathan, Shiyali R.amamrita. The Five Laws of Library Science. (London: Edward Goldston, Ltd,; Madras: Madras Library Association, 1993).

Sen, B K, "Ranganathan's Fife Laws" dalam Annals of Library and Information Studies, Vol, 55, June 2008, pp. 87-90.

Sri Rohyanti Zulaikha, "Kontribusi S.R.

Ranganathan dalam Perkembangan Ilmu Perpustakaan Dewasa Ini” dalam Fihris Jurnal Ilmu Perpustakaan dan Informasi Vol. III No. 1 (Januari-Juni 2008), (Yogyakarta: Jurusan IPI Fakultas Adab UIN Sunan Kalijaga, 2008).

Syihabuddin Qalyubi dkk., Dasar-dasar Ilmu Perpustakaan dan Informasi, (Yogyakarta: Jurusan Ilmu Perpustakaan dan Informasi Fakultas Adab, 2007).

Sulistyo-Basuki, Pengantar Ilmu Perpustakaan, (Jakarta: Penerbit PT Gramedia Pustaka Utama, 1993). 